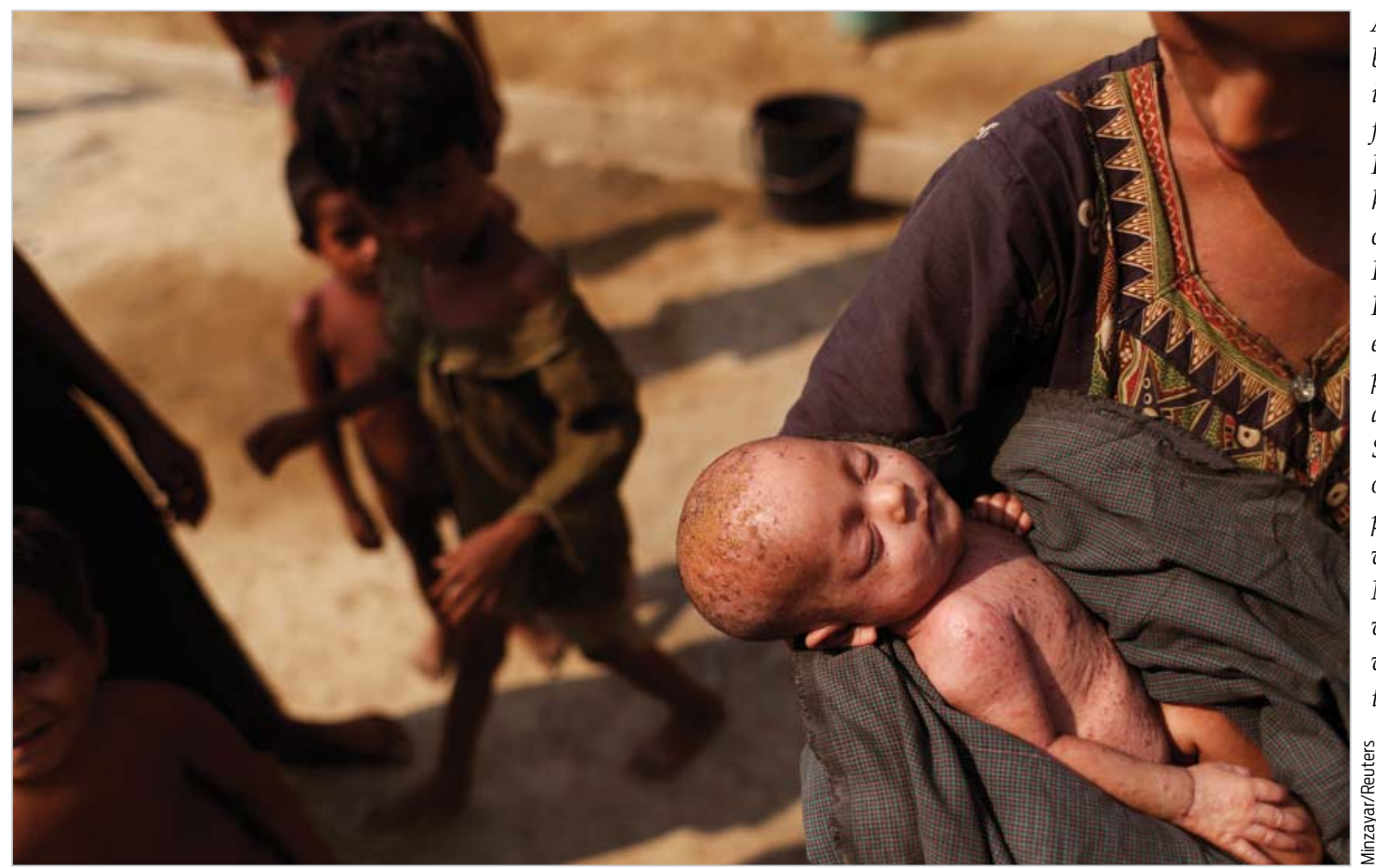

A Rohingya woman holds her baby, who is suffering from a skin infection, at a camp in Myanmar for internally displaced people. Restrictions on international aid have exacerbated a growing health crisis among stateless Muslim Rohingya in west Myanmar. In February, Myanmar's government expelled the main aid group providing health to more than half a million Rohingya, Médecins Sans Frontières-Holland, after the organisation said it had treated people believed to have been victims of violence. The United Nations says at least 40 Rohingya were killed by Buddhist Rakhine villagers. The government denies that any killings occurred.

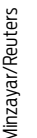

\title{
From the CSIRO
}

\section{Integrating genomics with health care}

With the completion of the first human genome sequence in 2003 (Nature 2004; 431: 931-945) came care. Now - 10 and a half years, a revolution in DNA sequencing technology and a millionfold reduction in the cost of sequencing a human genome later - the Melbourne Genomics Health Alliance (Melbourne Genomics) has been established to investigate the process, performance and impact of genomic sequencing as a tool in clinical care (http://www. melbournegenomics.org.au). The founding members are the Royal Melbourne Hospital, Royal Children's Hospital, Walter and Eliza Hall Institute, Murdoch Childrens Research Institute, University of Melbourne, Australian Genome Research Facility and the Commonwealth Scientific and Industrial Research Organisation (CSIRO) Preventative Health Flagship. the promise of a new era in health
A demonstration project is clinical workflows that integrate whole exome sequencing (WES) as a first-tier test in patient management. Each step, including counselling and consent of patients, sequencing, analysis and interpretation, return of results, and impact on clinical interpretation and patient management planning, will be analysed in detail. Outcomes for WES will be compared with standard investigations.

Both single gene mutations and combined effects of common gene variants that individually have little impact on disease are now recognised as significant contributors to heritable disease risk. Further, environmental factors interact with genotype to modify disease risk. For example, it is estimated that $70 \%$ of colorectal cancer cases could be avoided by modification of diet underway to develop and evaluate

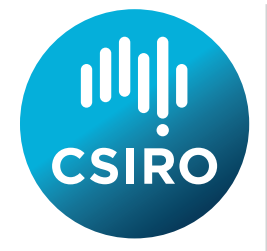

and lifestyle factors (Cancer Causes Control 2000; 11: 579-588). As a first step towards prevention through online engagement, participants with hereditary colorectal cancer will enter their own diet and lifestyle data online. The completeness of the data, concordance with other sources and linkage with genomic data and clinical records will be evaluated.

Melbourne Genomics has joined over 150 institutions worldwide in the Global Alliance for Genomics and Health, to enable the responsible sharing of genomic and clinical data. The international harmonisation of technical, operational and ethical standards that this alliance aims for is expected to greatly facilitate Melbourne Genomics' participation in major international research initiatives that will further advance developments in the personalisation of health care in Australia.
Trevor Locket

Theme Leader CSIRO Preventative Health Flagship

\section{Clara Gaff}

Program Leader Melbourne Genomics Health Alliance

doi: 10.5694/mjal4.00574 


\section{Labour induction linked with lower caesarean risk}

Induction of labour in women with at-term or post-term pregnancies has been associated with a reduced risk of caesarean delivery, according to research published in CMAJ. A systematic review of 157 randomised controlled trials published between 1975 and April $2012(n=31$ 085) found the overall risk of caesarean delivery was 12\% lower with labour induction than expectant management (relative risk $[R R]=0.88$ ). There was also a reduced risk of fetal death $(R R=0.50)$ and admission to a neonatal

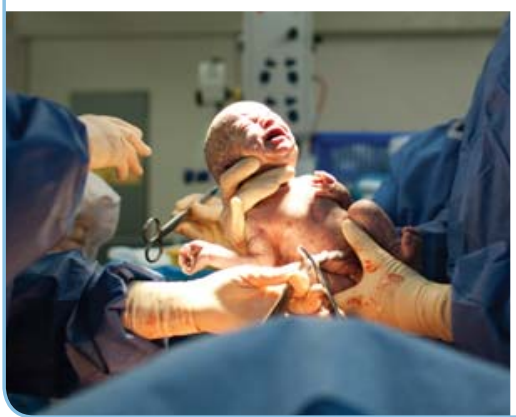
intensive care unit ( $R R=0.86)$, and there was no impact on maternal death $(R R=1.00)$. The findings, the authors wrote, were "contrary to prevalent beliefs and information from consumer organizations, guidelines and textbooks". "Our findings have implications for guidelines and the practice of obstetrics, and are reassuring for mothers, midwifes and obstetricians", they concluded.

CMAJ 2014; 28 April (online). doi: 10.1503/cmaj.130925

\section{Media coverage linked with youth suicide clusters}

Media portrayals of suicide may play a role in the emergence of teenage suicide clusters, according to research published in Lancet Psychiatry. The authors identified suicide clusters in 13-20-year-olds in US communities from 1988 to 1996, matched them with non-cluster control communities that had suicides with similar demographics but were not linked to each other, and compared newspaper stories published between the first and second suicides in a cluster. Significantly more news stories about suicidal individuals were published after a suicide that was followed by linked deaths than after a suicide with no subsequent linked suicides. Newspaper stories following the index cluster suicide were published more prominently (front page, presence of a picture, headline containing the word suicide, details of method, presence of a note). An accompanying commentary said "incautious newspaper reporting of suicide might compound the risk of an individual suicide becoming part of a cluster, at least in young people". The editorial suggested the next step was to investigate the effect of the internet.

Lancet Psychiatry 2014; 2 May (online). doi: 10.1016/S2215-0366(14)70225-1

doi: 10.1016/S2215-0366(14)70227-5

\section{Time the best antidote for new anticoagulants}

Perioperative management of patients taking novel anticoagulants (NOACs) requires knowledge of time of last intake and dosage, particularly in emergency and elective conditions, according to a narrative review published in the British Journal of Surgery. The lack of antidotes for NOACs means the risk of major bleeding events must be assessed and accounted for when performing surgery, the authors wrote. The shorter half-life, compared with warfarin, means "time is the most important antidote", they wrote. The review assessed each of the three

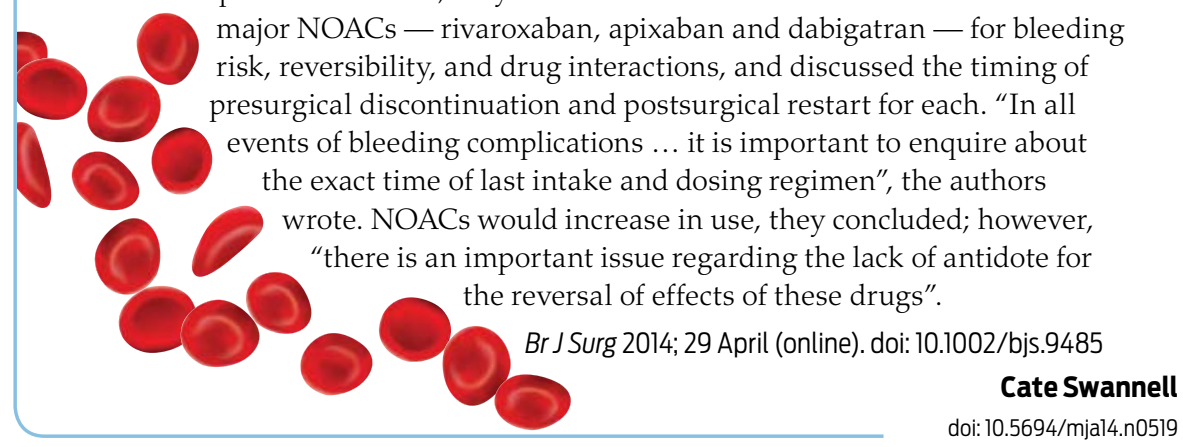

This issue's suggested topic:

Do you consider climate change to be a matter of medical concern?

\section{ERF White Paper}

The Direct Action Emissions Reduction Fund (ERF) may work (details are sparse), but alone it is insufficient to credibly reduce Australia's greenhouse gas emissions by the 19\% (from 2000) that the Climate Change Authority, based on assessment of the science and economics, conservatively recommends. The ERF White Paper doggedly sticks to 5\%. Ross Garnaut suggests even that is ambitious. To grasp this opportunity to modernise our economy, prepare Australia to compete internationally and protect our citizens from heatwaves, drought and flooding rains, mitigating greenhouse gas emissions requires a broad and integrated set of policy responses. Government should take this approach.

Dr Peter Tait

General Practitioner, ACT.

Email us a brief comment (no more than 100 words) on any healthrelated subject. Email your comments to: comments@mja.com.au When sending your comment, please include your full name, discipline and state of residence, and disclose any relevant information or affiliations that may affect interpretation of your comments.

Visit: https://www.mja.com.au/journal/mja-instructions-authorstypes-articles-published-mja\#Comments

\section{MJA InSight poll Total respondents: 171}

Based on the findings of the NHMRC review, should homeopathy be excluded from private health insurance?
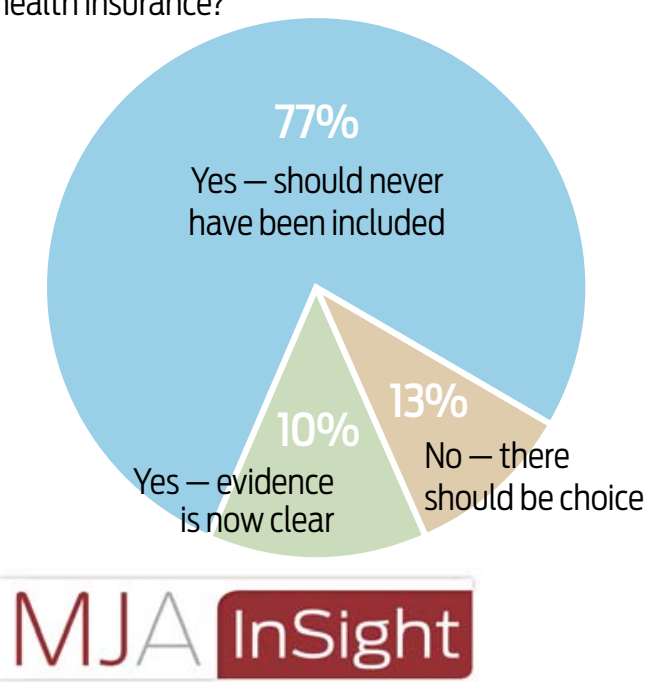

Take part in next week's poll on: www.mja.com.au/insight 